\title{
THE ASCIDIANS TRIDIDEMNUM ALLENI AND DISTAPLIA GARSTANGI, NEW SPECIES FROM THE PLYMOUTH AREA
}

\author{
By N. J. Berrill \\ From the Plymouth Laboratory and McGill University, Montreal
}

(Text-figs. I-3)

Two ascidians have been collected in the region of Plymouth that do not fit the descriptions of known species sufficiently well to be identified with them. They are species of Trididemnum and Distaplia.

These genera are represented in waters around the British Isles only by Trididemnum tenerum (Verrill) and Distaplia rosea Della Valle. If Trididemnum niveum should be a valid species and not a synonym for $T$. tenerum as considered by Hartmeyer (I924), it also is probably present. Accordingly, any species that cannot be identified with these forms must either be new, or must represent geographical extensions of species not previously recorded. In this last respect, the possibility of the Mediterranean Distaplia magnilarva reaching the western Channel must be considered. As the following discussions indicate, the conclusions are that the two forms described here cannot be properly identified with any of the above and are to be treated as new species.

Trididemnum alleni $\mathrm{n.sp}$. is named after the late Dr E. J. Allen, so long the inspiring and humane director of the Plymouth Laboratory, while Distaplia garstangi n.sp. is so named as a small tribute to Professor Walter Garstang for his pioneering interest in the ascidians of Plymouth waters.

\section{TRIDIDEMNUM ALLENI sp.nov.}

Colonies are usually small, less than a centimetre in greatest length, and about $3 \mathrm{~mm}$. thick. They are brilliantly white, an appearance retained even in preserved specimens of long standing. The surface is uneven. They are commonly attached to Eunicella and larger hydroids such as Antennularia at depths of from Io to $30 \mathrm{~m}$., and have been recorded with certainty only from the Plymouth area of the English Channel.

The dense white opacity of the colony is due to the presence of enormous numbers of calcareous spicules lying beneath a more superficial layer of bladder cells, together forming a light-reflecting layer. The density is such that the contained zooids are very hard to distinguish, and stained sections were found to be necessary for adequate examination.

The zooid is, in general, like those of most didemnids, but is distinctive in the proportions of its thorax, oesophagus and abdomen. The abdomen is 
large, the oesophageal region long and slender, while the thorax is exceptionally small. There are three rows of stigmata as in all species of Trididemnum. There are seven to eight stigmata per row. The endostyle is as wide as the small branchial sac as a whole. The branchial siphon has eight lobes. The atrial siphon is relatively wide, while absolutely small, and is almost flush with the mid-dorsal surface of the thorax, although the six lobes are still discernible. The thoracic organ on each side is small, without noticeably raised margin.

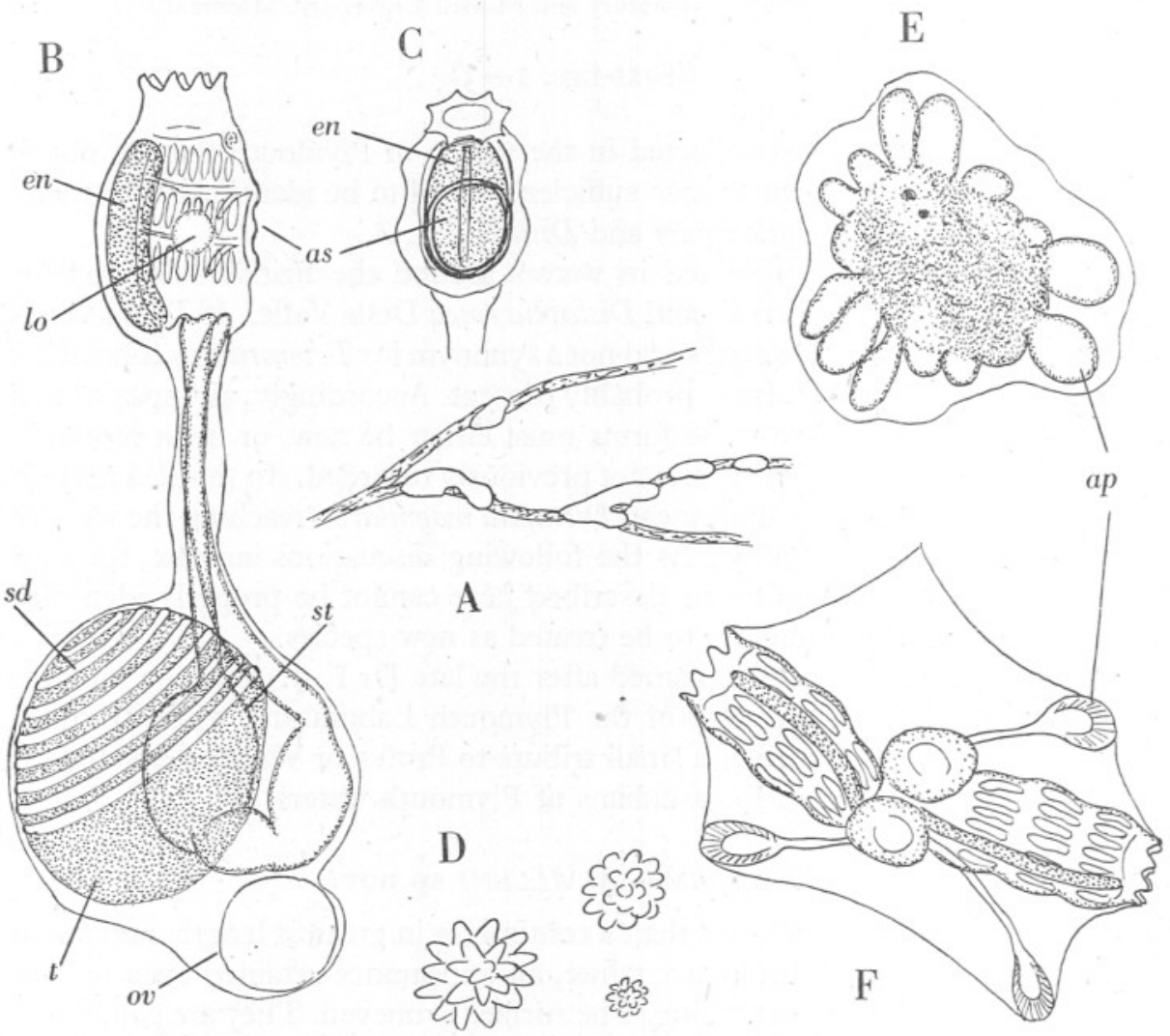

Fig. I. Trididemnum alleni. A, colonies attached to Gorgonia branches, natural size. $\mathrm{B}$, mature zooid showing relative proportions of thorax, oesophagus and abdomen, and general structure, from left side. C, thorax from dorsal side showing relative width of endostyle. D, spicules from common test. E, metamorphosing larva with numerous epidermal ampullae. F, completely metamorphosed individual when just active, with oozooid and first blastozooid equally developed. ap, ampulla; as, atrial siphon; $e n$, endostyle; lo, lateral organ; ov, ovary; $s d$, sperm duct; st, stomach; $t$, testis.

The oesophageal region is very narrow and is as long as, or longer than, the thorax. The abdomen is relatively large, a great part consisting of the comparatively enormous testis. The sperm duct coils spirally around the single undivided testis about eight times. The epidermal ampullae, growing from the 
mid-abdominal region, are small and hardly project beyond the silhouette of the whole zooid. They were seen only in sectioned material.

The above description is accordingly of a form that can hardly be identified with either Trididemnum tenerum or T. niveum. Hartmeyer assumes T. niveum to be a synonym of $T$.tenerum, though it is not at all certain that this is so. They are undoubtedly very similar. T. tenerum may contain spicules or may be entirely free of them. T. niveum, recorded with certainty only from the Mediterranean, and the French Atlantic coast, possesses the same striking external appearance of the form here described, which in fact is the only reason for suspecting that they may be identical.
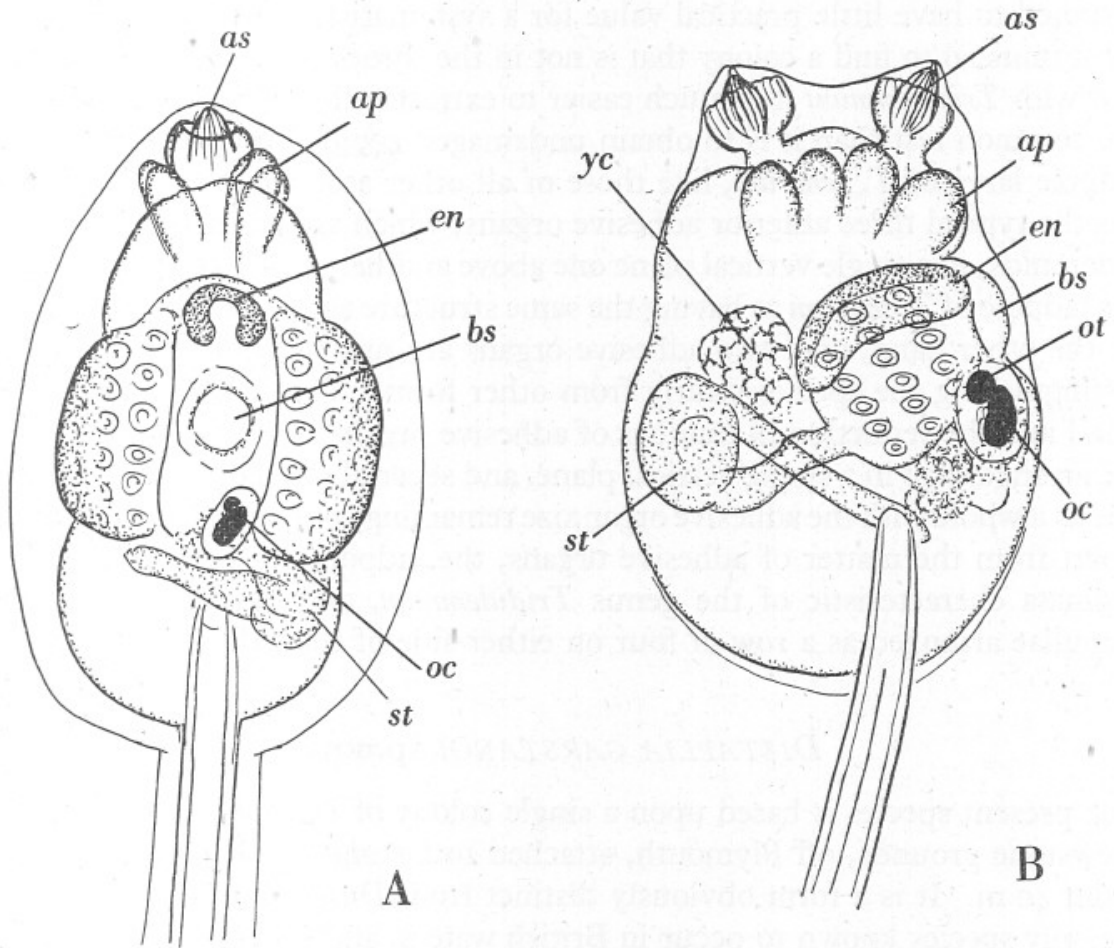

Fig. 2. Tadpole of Trididemnum alleni. A, from dorsal side. B, from left side. ap, ampulla; $a s$, atrial siphon; $b s$, branchial siphon; en, endostyle; oc, ocellus; ot, otolith; st, stomach; $y c$, yolky cells associated with subsequent development of first blastozooid.

Lahille (I890), describing T. niveum, speaks of lateral thoracic organs being very clearly seen, and of five epidermal ampullae with voluminous terminals. In the Plymouth form both of these structures, though present, are extremely difficult to distinguish. In $T$. tenerum they are also strongly developed, so that $T$. alleni differs from both the other species in the same respect. According to Lahille, and to Harant \& Vernières (1933), T. tenerum and T. niveum differ from one another not only in zooid proportions but in that the former has a 
sperm duct with about a dozen spiral turns, the latter only eight. This has been confirmed for $T$. tenerum taken at Plymouth. So it only remains to discuss the question of identity between $T$. alleni and $T$. niveum. If Harant's illustration of $T$. niveum is accepted as typical, the body proportions are the reverse of $T$. alleni, the thorax being considerably larger than the abdomen and the oesophageal region being shorter than either. Moreover, the atrial siphon is situated in a decidedly more posterior position relative to the anus and rows of stigmata. Accordingly, on grounds of adult structure alone, identity of $T$. alleni with either $T$. tenerum or $T$. niveum is rejected.

The tadpole larvae are even more distinctive. As a rule, larval characters are assumed to have little practical value for a systematist, but in didemnids it is most unusual to find a colony that is not in the throes of sexual reproduction, and with Trididemnum it is much easier to extract fully-formed tadpoles from the common test than it is to obtain undamaged zooids for examination. The tadpole larva of $T$. tenerum, like those of all other ascidians so far described, has the typical three anterior adhesive organs, which are arranged, as in other didemnids, in a single vertical plane one above another. Salensky (I895) shows the tadpole of $T$. niveum as having the same structure as $T$. tenerum. In T. alleni on the other hand, only two adhesive organs are present, a unique condition distinguishing the species clearly from other forms. The tadpole is relatively small and the reduction in number of adhesive organs is due probably first to the arrangement in a single vertical plane, and secondly to reduction in tadpole size as a whole with the adhesive organ size remaining comparatively unaffected. Apart from the matter of adhesive organs, the tadpole has the three rows of stigmata characteristic of the genus Trididemnum, and has eight epidermal ampullae arranged as a row of four on either side of the adhesive organs.

\section{DISTAPLIA GARSTANGI sp.nov.}

The present species is based upon a single colony of Distaplia taken from the Mewstone grounds, off Plymouth, attached to a stone amidst shell gravel, in about $40 \mathrm{~m}$. It is a form obviously distinct from Distaplia rosea Della Valle, the only species known to occur in British waters, and it cannot be identified either with $D$. magnilarva Della Valle, a Mediterranean species that might conceivably reach the western end of the Channel, though there are no records of it from the west or north-west coast of France, or with D. clavata (Sars), a northern species that apparently does not extend south even into Scottish waters.

Zooids of Distaplia species do not differ very markedly from one another, and while generically they are very easily recognized, specific distinctions are relatively difficult. Colonies, however, show specific characteristics. In the present instance it is in the form of the colony that the distinction mainly lies; and since differences in both zooid and tadpole can with care be distinguished, the new species seems to be justified. 


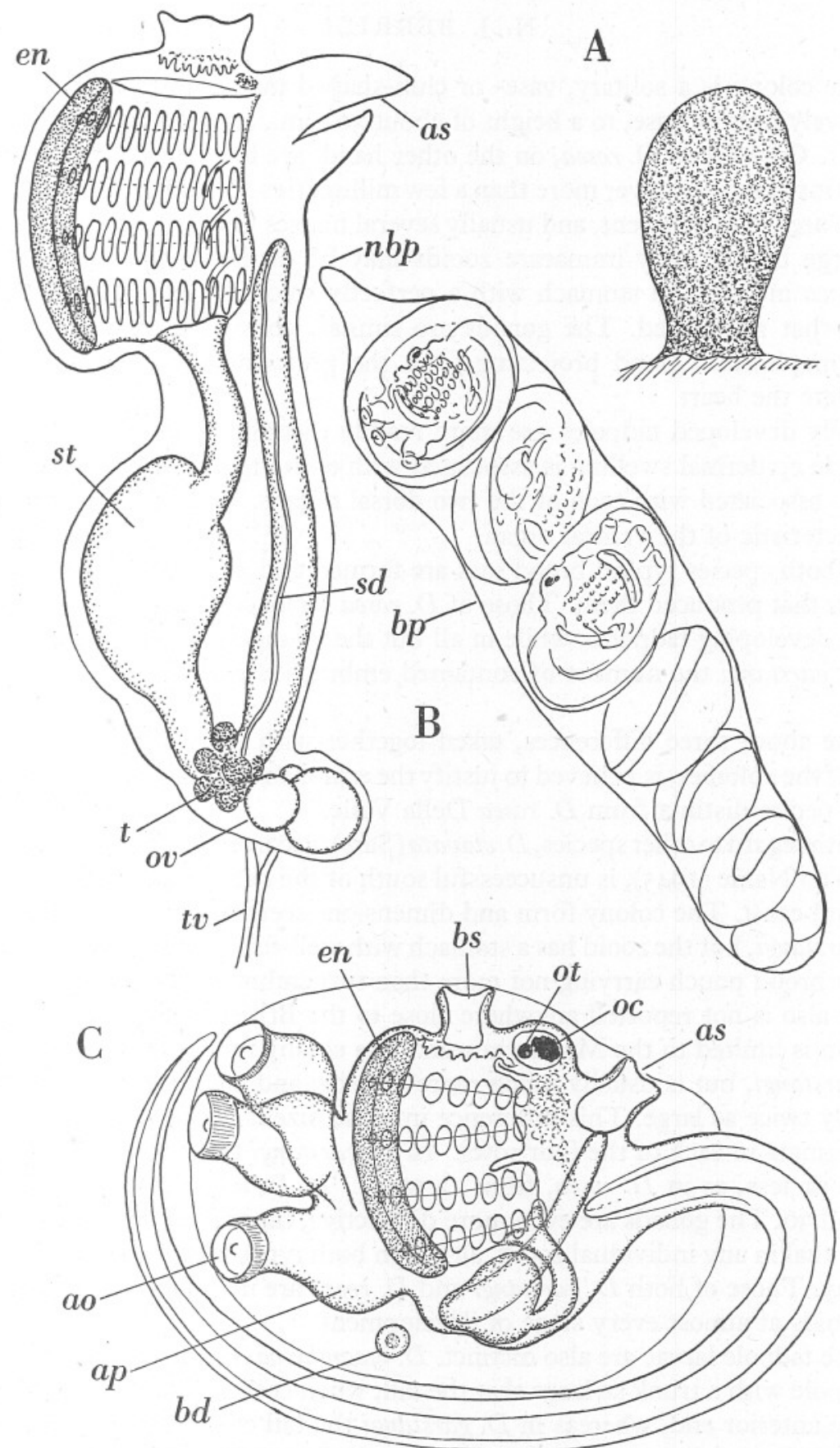

Fig. 3. Distaplia garstangi. A, whole colony, natural size. B, mature zooid with fully developed brood pouch just detached. C, tadpole from left side. ao, adhesive organ; $a p$, ampulla; $a s$, atrial siphon; $b d$, bud; $b p$, brood pouch; $b s$, branchial siphon; $e n$, endostyle; $n b p$, neck of brood pouch; oc, ocellus; ot, otolith; ov, ovary; sd, sperm duct; $s t$, stomach; $t$, testis; $t v$, test vessels. 
The colony is a solitary, vase- or club-shaped mass, growing erect from a relatively narrow base, to a height of about $30 \mathrm{~mm}$., and of a yellowish-brown colour. Colonies of $D$. rosea, on the other hand, are low, consisting of pink or rose-tinted masses never more than a few millimetres in height, with a relatively broad area of attachment, and usually several masses united by narrow strands.

Large but sexually immature zooids may be distinguished from those of D. rosea in having a stomach with a perfectly smooth wall, instead of being somewhat reticulated. The gonads are similar, consisting in both forms of a hermaphrodite gland projecting from the posterior abdomen on the side opposite the heart.

Fully developed tadpoles are more readily distinguished. In D. garstangi a single epidermal swelling is associated with each organ. In $D$. rosea a single one is associated with each of the two dorsal organs, but a double ampulla is characteristic of the ventral organ.

In both species typical brood sacs are formed and may survive the parental zooids that produced them. Those of $D$. rosea rarely contain more than two or three developing tadpoles, while in all but the youngest pouch-bearing zooids of $D$. garstangi the number of contained embryos is rarely less than seven or eight.

The above three differences, taken together with the distinctive form and size of the colonies, is believed to justify the establishment of Distaplia garstangi as a species distinct from $D$. rosea Della Valle.

With regard to other species, D. clavata (Sars), according to Thompson (I934) and Van Name (1945), is unsuccessful south of the deeper water off the North Iceland coast. The colony form and dimensions seem to be similar to those of $D$. garstangi, but the zooid has a stomach with well-formed reticulate markings, and a brood pouch carrying not more than two embryos. D. magnilarva Della Valle also is not reported anywhere close to the British Isles, and as far as is known is limited to the Mediterranean. The colony form is not unlike that of D. garstangi, but is usually much more massive and contains zooids approximately twice as large. This difference in zooid size is reflected in the number of stigmata in each of the four rows. In D. garstangi the number is the same, more or less, as in D. rosea, from I2 to I5. In D. magnilarva it is between 25 and 30 . The gonads are even more distinctive, those of $D$. magnilarva being unisexual in any individual zooid, although both types may coexist in the same colony. Those of both $D$. garstangi and $D$. rosea are invariably hermaphrodite in zooids at almost every stage of development.

The tadpole larvae are also distinct. D. magnilarva, as the name implies, has a tadpole with a trunk so large that the tail, when coiled, reaches only half way to the anterior end, whereas in D. garstangi the tail of the tadpole can extend around the anterior tip of the trunk and a little way beyond. 


\section{REFERENCES}

Della Valle, A., i882. Distaplia, nouveau genre de Synascidies. Arch. Ital. Biol., T. I, pp. 193-203.

Harant, H. \& VerniÈres, P., I933. Tuniciers. In Faune de France, T. xxvir, pp. I-99. Hartmeyer, R., I924. Ascidiacea, Pt. II. Danish Ingolf. Exped., Bd. II, Pt. 7, pp. I275.

Lahille, F., I890. Recherches Tuniciers. Toulouse.

Salensky, W., I895. Ueber die Entwicklung von Didemnum niveum. Mitt. zool. Stat. Neapel, Bd. xI, pp. 488-630.

Thompson, H., I934. Tunicata of the Scottish area. Pt. IV. Fisheries, Scotland, Sci. Invest., I934, No. I, pp. I-44.

VAn NAme, W. G., I945. The North and South American ascidians. Bull. Amer. Mus. Nat. Hist., Vol. Lxxxiv, pp. I-476. 